\title{
HUBUNGAN LOCUS OF CONTROL DAN DUKUNGAN SOSIAL DENGAN COLLEGE ADJUSMENT TERHADAP MAHASISWA FAKULTAS KEDOKTERAN UMUM UNIVERSITAS MALAHAYATI ANGKATAN TAHUN 2019
}

\section{Mohammad Ridho Irawan ${ }^{1 *}$, Asri Mutiara Putri ${ }^{2}$, Sri Maria Puji Lestari ${ }^{3}$, Achmad Farich ${ }^{4}$}

${ }^{1 *}$ Medical Student, Faculty of Medicine, Malahayati University, Lampung
${ }^{2,3,4}$ Teaching staff, Faculty of Medicine, Malahayati University, Lampung

Email Koresponden: Ridho@gmail.com

\section{ABSTRACT: RELATIONSHIP OF LOCUS OF CONTROL AND SOCIAL SUPPORT WITH COLLEGE ADJUSMENT FOR STUDENTS OF THE FACULTY OF GENERAL MEDICINE, MALAHAYATI UNIVERSITY IN 2019}

Background: New students are faced with new, unfamiliar situations and a new life full of challenges, while on the other hand they have various old experiences and habits that are not necessarily suitable for their new life. The support that students feel from their friendship can contribute to the student adjustment process in higher education.

Research objectives: To find out the relationship between locus of control and social support with collage adjustment for students of the Faculty of Medicine, Malahayati University in 2019.

Methods: This type of research is quantitative, analytic observational design with a cross sectional approach. The sample was selected by simple random sampling. The sample was 107 respondents. Retrieval of data using a questionnaire sheet. The data analysis technique used pearson correlation.

Results: Statistical test result using chi-square test found a significant corelation between locus of control and social support with collage adjustment for students of Faculty of Medicine, Malahayati University in 2019 with $p$-value $=0.000(p<$ 0,05).

Conclusion: There is a relationship between Locus Of Control and Social Support with Collage Adjusment for Students of the Faculty of Medicine, Malahayati University in 2019.

Keywords: Locus Of Control, Social Support, Collage Adjusment

\section{ABSTRAK: HUBUNGAN LOCUS OF CONTROL DAN DUKUNGAN SOSIAL DENGAN COLLEGE ADJUSMENT TERHADAP MAHASISWA FAKULTAS KEDOKTERAN UMUM UNIVERSITAS MALAHAYATI ANGKATAN TAHUN 2019}

Latar Belakang :Mahasiswa baru dihadapkan pada situasi baru yang asing dan suatu kehidupan baru yang penuh dengan tantangan, sedangkan di sisi lain mereka memiliki berbagai pengalaman dan kebiasaan lama yang belum tentu sesuai dengan kehidupan baru mereka. Penyesuaian diri di perguruan tinggi juga dipengaruhi oleh kemampuan mahasiswa dalam mengendalikan dirinya dikenal dengan locus of control. Dukungan yang dirasakan oleh mahasiswa dari hubungan pertemanan mereka dapat memberikan kontribusi terhadap proses penyesuaian mahasiswa di perguruan tinggi. 
Tujuan penelitian: Diketahui hubungan locus of control dan dukungan sosial dengan collage adjusment terhadap Mahasiswa Fakultas Kedokteran Universitas Malahayati tahun 2019.

Metode Penelitian :Jenis penelitian kuantitatif, rancangan analitik observasional dengan pendekatan cross sectional. Pengambilan sampel dengan menggukanan teknik simple random sampling dengan jumlah sampel 107 orang. Pengambilan data menggunakan lembar kuesioner. Teknik analisis data menggunakan uji pearson correlation.

Hasil penelitian : Data dianalisis secara univariat dan bivariat. Hasil uji statistik menggunakan uji pearson correlation didapatkan hubungan yang bermakna antara locus of control dan dukungan sosial dengan college adjustment pada mahasiswa Fakultas Kedokteran Universitas Malahayati angkatan 2019 dengan nilai $p=0.000(p<0,05)$.

Kesimpulan : Ada hubungan bermakna antara locus of control dan dukungan sosial dengan collage adjusment terhadap mahasiswa Fakultas Kedokteran Universitas Malahayati angkatan tahun 2019.

Kata Kunci : Locus Of Control, Dukungan Sosial, Collage Adjusment

\section{PENDAHULUAN}

Menyesuaikan diri di perguruan tinggi selepas bangku sekolah menengah dapat menjadi transisi yang sulit bagi banyak mahasiswa. Masa transisi dari bangku sekolah menuju bangku perkuliahan adalah sebuah proses yang kompleks. Di Indonesia, sebagian besar remaja yang lulus dari sekolah menengah, melanjutkan pendidikannya hingga ke perguruan tinggi (Monks, 2012). Keputusan untuk melanjutkan pendidikan ke jenjang pendidikan tinggi sendiri memiliki berbagai alasan. Dari keinginan untuk mengenyam pendidikan tinggi, memperoleh gelar, menambah pengetahuan, hingga pengembangan diri (Sharma, 2012). Perguruan tinggi bukanlah sekadar jalur pendidikan lanjutan dari sekolah menengah.

$$
\text { Menurut Salam (2014), }
$$

perguruan tinggi merupakan suatu yang hakiki dari taraf pendidikan tinggi sesuai dengan tuntutan dari pendidikan tinggi. Memasuki perguruan tinggi berarti melibatkan diri di dalam situasi hidup dan situasi akademis yang secara fundamental berbeda dengan apa yang pernah dialami dalam lingkungan sekolah menengah. Konsekuensinya, manusia wajib melakukan adaptasi dengan dunia baru yang penuh dengan likuliku dan seluk beluk serta penuh resiko, khususnya adaptasi pola berpikir, belajar, berkreasi dan bertindak dalam menjalani kehidupan di kampus. Menurut White \& Watt (dalam Gutama, 2014) penyesuaian diri yang paling nampak pada mahasiswa baru berkaitan dengan sistem pembelajaran yang berbeda dengan sekolah menengah. Proses pembelajarannya yang berlangsung lebih cepat, tuntutan akan pemahaman yang lebih mendalam terhadap materi, materi pembelajaran yang berbeda dengan sekolah menengah, cara mengajar dosen, pengurusan perkuliahan yang dilakukan secara mandiri oleh mahasiswa; hal-hal tersebut menyebabkan mahasiswa baru membutuhkan proses dalam menghadapi perubahan-perubahan yang terjadi di perguruan tinggi. Selain itu, mahasiswa baru dituntut untuk dapat mengerti tentang tata etika yang berlaku dalam lingkungan kampus, khususnya tentang asas-asas 
etika kehidupan kampus yang ideal dan yang dapat dikembangkan dalam lingkungan masyarakat kampus. Mahasiswa baru diharapkan untuk tidak memiliki perilaku-perilaku yang menyimpang dan kejahatan yang bertentangan dengan etika kehidupan kampus. Etika kehidupan kampus ini ingin mengantarkan mahasiswa baru agar memiliki sikap dan perilaku yang tertib, teratur, dan kondusif bagi mahasiswa untuk mengikuti pendidikan selama duduk sebagai mahasiswa (Sujana, 2014). Hurlock mengungkapkan bahwa salah satu tugas perkembangan masa remaja yang paling sulit berhubungan dengan penyesuaiansosial. Meskipun tidak semua remaja mengalami masa badai dan tekanan, namun sebagian besar remaja mengalami ketidakstabilan dari waktu ke waktu sebagai konsekuensi dari usaha penyesuaian diri pada pola perilaku baru dan harapan sosial yang baru. Hal ini tentunya memicu timbulnya berbagai permasalahan bagi mahasiswa baru sebagai remaja. Dari beberapa hasil wawancara terhadap mahasiswa baru angkatan 2013 di Universitas Airlangga menunjukkan bahwa terdapat permasalahan penyesuaian sosial terhadap lingkungan perguruan tinggi pada mahasiswa baru di Universitas Airlangga.

Perbedaan-perbedaan yang mereka rasakan, transisi dari dunia sekolah menuju dunia perkuliahan ini, menjadi pemicu utama munculnya berbagai permasalahan mahasiswa baru. Beberapa hal yang dapat mempengaruhi performa individu di perguruan tinggi, diantaranya lokasi, kebiasaan belajar, jarak dari rumah dan faktor personal lainnya (Morgans, 2012). White \& Watt (dalam Gutama, 2014) menyebutkan, mahasiswa baru lebih sering mengalami gangguan perilaku karena mereka berada pada masa transisi. Mahasiswa baru dihadapkan pada situasi baru yang asing dan suatu kehidupan baru yang penuh dengan tantangan, sedangkan di sisi lain mereka memiliki berbagai pengalaman dan kebiasaan lama yang belum tentu sesuai dengan kehidupan baru mereka. Keberhasilan di perguruan tinggi tidak hanya dikaitkan dengan kurikulum dan jumlah waktu belajar saja, faktor lingkungan dari perguruan tinggi pun ikut mempengaruhi keberhasilan, seperti pola interaksi dosen pengajar dengan mahasiswa, mahasiswa dengan teman sebaya, dan lain-lain. Dengan kata lain, aspek perguruan tinggi sebagai suatu sistem sosial turut berperan terhadap pencapaian prestasi mahasiswa.

Sebuah studi oleh Brier dan Paul (2011) merujuk pada aspek "friendsickness" sebagai sebuah determinan dari penyesuaian diri seseorang di perguruan tinggi. Mereka menggagas hal ini dari studi sebelumnya yang menyatakan bahwa ketika seseorang kehilangan kelompok teman akrab mereka, dan mereka berada pada lingkungan yang tidak akrab, akan muncul perasaan sedih secara emosional dan rasa kehilangan yang mendalam. Para peneliti menyimpulkan bahwa semakin erat sebuah kelompok pertemanan, maka semakin sulit pula bagi para anggotanya untuk berubah tanpa temanteman lama mereka. Hal ini menunjukkan bahwa diantara bagian yang tersulit dari penyesuaian sosial mahasiswa baru adalah meningkatnya pengaruh dari kelompok sebaya dalam perubahan perilaku sosial, pengelompokan sosial yang baru, nilai-nilai baru, serta penolakan dari lingkungan sosial yang baru (Nurdin, 2019). Penyesuaian ke perguruan tinggi terdiri dari berbagai tuntutan yang berbeda dalam bentuk dan tingkatan, serta membutuhkan banyak respon coping atau penyesuaian (Sharma, 2012). 
Dalam menghadapi permasalahan-permasalahan ini, terdapat mahasiswa yang mampu menyesuaikan diri dengan mudah namun ada pula mahasiswa yang mengalami kesulitan. Kemampuan dalam mengembangkan hubungan yang baru dan efektif dengan lingkungan, dapat menjadi elemen penting dari penyesuaian sosial. Menurut Schneiders (1964), kondisi kemampuan penyesuaian diri dan sosial individu yang berbeda-beda dapat disebabkan oleh beberapa faktor, yakni kondisi fisik, perkembangan dan kematangan, faktor psikologis, kondisi lingkungan, dan faktor budaya. Kondisi lingkungan di sini meliputi kondisi rumah, keluarga, dan sekolah, baik itu lingkungan fisik maupun lingkungan sosial. Ketika berhadapan dengan lingkungan baru, mahasiswa membutuhkan dukungan sosial yang tinggi agar dapat menyesuaikan diri terhadap lingkungan perguruan tinggi, baik secara akademik maupun sosial.

Penyesuaian yang baik adalah penyesuaian yang ditandai dengan adanya pengetahuan dan pandangan terhadap diri sendiri dan orang lain; adanya obyektivitas dan penerimaan sosial; pengendalian diri dan perkembangan diri yang baik; memiliki tujuan dan arah yang jelas; memiliki sudut pandang, penilaian dan pandangan hidup yang memadai; memiliki rasa humor; memiliki rasa tanggung jawab sosial; memiliki kemampuan untuk bekerja sama dan menaruh minat terhadap orang lain; memiliki minat yang besar dalam melakukan pekerjaan dan bermain; memiliki perkembangan kebiasaan yang baik; adaptabilitas, memiliki kepuasan dalam bekerja dan bermain; serta memiliki orientasi yang menandai adanya realitas sosial (Schneiders, 2014).

Arkoff (2013) meyakini bahwa penyesuaian diri di perguruan tinggi mencerminkan tentang bagaimana seorang individu mencapai tuntutantuntutan yang ada dan memberi dampak terhadap pertumbuhan pribadinya.Lapsley, Rice, \& FitzGerald (2010) mengungkapkan bahwa untuk dapat melewati masa transisi ini dengan baik, dibutuhkan tingkat adaptasi yang tinggi dari remaja. Selaras dengan pernyataan di atas Tinto (2013) mengungkapkan, kemampuan dalam mengatur dan menyeimbangkan antara kehidupan sosial dan akademik dapat membantu proses penyesuaian diri pada mahasiswa di lingkungan perguruan tinggi. Dukungan sosial yang baik dari lingkungan dapat membantu mahasiswa baru dalam mengatasi permasalahan-permasalahan dan menghadapi masa transisinya dengan baik (Cutrona, 2016). Individu dengan lingkungan sosial yang penuh dukungan emosional, instrumental maupun informasi yang baik ketika mereka membutuhkan, menunjukkan tingkatanstres dan gejala depresi yang lebih rendah dalam menghadapi peristiwa hidup dibandingkan dengan mereka yang tidak (Thoits, 2015). Sarason (2010) menyatakan bahwa dukungan sosial yang diperoleh individu berasal dari lingkungan keluarga dan teman sebaya. Mahasiswa baru yang meninggalkan lingkungan keluarganya untuk belajar di perguruan tinggi, praktis lebih sering berinteraksi dengan lingkungan teman sebayanya. Martin, Swartz Kulstad, dan Madson (2009) menemukan, dukungan yang dirasakan oleh mahasiswa dari hubungan pertemanan mereka dapat memberikan kontribusi terhadap proses penyesuaian mahasiswa di perguruan tinggi.

Dukungan sosial dari teman sebaya merupakan faktor pembentuk penyesuaian sosial terhadap lingkungan perguruan tinggi yang 
penting, karena teman sebaya dapat bertindak sebagai panutan, menjadi acuan grup, seorang pendengar, seseorang yang dapat mengerti, seorang kritikus, seorang penasihat, dan seorang pendamping (Tokuno, 2016). Brissette, Scheier, \& Carver (2012) mengutarakan, ada kemungkinan bahwa perbedaan kualitas lingkungan sosial berdampak secara kritis terhadap tingkat penyesuaian diri yang lebih baik. Hal ini dapat berarti, kualitas lingkungan sosial yang tinggi mampu memberikan tingkat kepuasan terhadap dukungan sosial yang lebih tinggi daripada kualitas lingkungan sosial yang rendah. Semakin tinggi kualitas lingkungan sosial yang dimiliki, maka semakin tinggi pula tingkat kepuasan terhadap dukungan sosial yang dimiliki.Semakin rendah kualitas lingkungan sosial yang dimiliki, maka semakin rendah pula tingkat kepuasan terhadap dukungan sosial yang dimiliki. Tinggi rendahnya tingkat kepuasan terhadap lingkungan sosial dapat mempengaruhi pola perilaku yang ditunjukkan oleh individu terhadap lingkungan sosialnya, maka dalam hal ini kualitas dari lingkungan sosial dapat memberikan dampak terhadap kemampuan penyesuaian sosial dari individu, dalam penelitian ini khususnya pada lingkungan perguruan tinggi dari mahasiswa baru. Berdasarkan penelitian Budiyanto (2015) tentang hubungan antara dukungan sosial dengan penyesuaian diri di lingkungan kampus pada mahasiswa Fakultas Psikologi Universitas Padjadjaran, diketahui bahwa terdapat hubungan antara dukungan sosial dengan penyesuaian diri di lingkungan kampus dengan koefiesien korelasi $(r)$ sebesar 0.635. Artinya, semakin tinggi dukungan sosial yang diberikan atau diterima oleh mahasiswa, maka semakin tinggi pula kemampuan penyesuaian diri mahasiswa di lingkungan kampus.
Kemampuan penyesuaian diri di lingkungan kampus ditentukan oleh dukungan sosial $\left(r^{2}\right)$ sebesar $40.32 \%$ dan sisanya ditentukan oleh faktor lainnya.

Penyesuaian diri di perguruan tinggi juga dipengaruhi oleh kemampuan mahasiswa dalam mengendalikan dirinya. Kemampuan ini dikenal dengan locus of control. Locus of control menjadi faktor yang penting dalam menentukan bagaimana mahasiswa baru akan menyesuaikan diri melalui pemaknaan situasi menekan di perguruan tinggi (Crede \& Nichorster, 2012). Rotter (1966) mengungkapkan seorang individu dapat memaknai peristiwa yang terjadi dalam hidupnya sebagai hal yang bergantung pada faktor dalam dirinya sendiri (locus of control internal), atau memaknai peristiwa tersebut sebagai hal yang terjadi karena pengaruh dari luar dirinya seperti takdir dan pengaruh orang lain (locus of control eksternal). Individu dengan locus of control internal diketahui cenderung memaknai peristiwa yang terjadi dalam hidupnya sebagai hal yang dapat dikendalikan (Lefcourt, 1991). Dalam konteks kehidupan di perguruan tinggi, pemaknaan terhadap tuntutan di perguruan tinggi juga akan dilakukan oleh mahasiswa tahun pertama sebelum menentukan bagaimana cara mahasiswa tersebut merespon tuntutan itusendiri. Mahasiswa tahun pertama yang memaknai tuntutan di perguruan tinggi sebagai hal yang dapat dikendalikan, atau disebut memiliki locus of control internal, akan memutuskan tindakan yang efektif dalam menghadapi situasi tersebut dan mempertimbangkan konsekuensinya. Dengan kata lain, mahasiswa dengan locus of control internal akan cenderung merespon tuntutan tersebut dengan berusaha menyesuaiankan dirinya di perguruan tinggi. Oleh karena itu, dalam 
penelitian ini peneliti berfokus pada faktor locus of control.

Locus of control merupakan sebuah kecenderungan yang bersifat dinamis dan dapat berubah seiring bertambahnya usia individu. Penelitian yang dilakukan oleh Crandall, Katkovsky, dan Crandall (1965) menunjukkan semakin bertambahnya usia individu maka kecenderungan locus of control yang dimilikinya semakin internal sesuai dengan tingkat kedewasaan individu tersebut. Hal ini menunjukkan bahwa locus of control merupakan faktor yang masih dapat dikembangkan pada diri individu. Oleh karena itu, dengan menguji hubungan antara locus of control internal dan penyesuaian diri di perguruan tinggi maka dapat diketahui peran locus of control internal terhadap penyesuaian diri di perguruan tinggi.

Penelitian-penelitian

terdahulu terkait locus of control internal pada mahasiswa telah menunjukkan kaitan locus of control internal terhadap karakteristik individu yang memiliki penyesuaian diri yang baik di perguruan tinggi. Akan tetapi, penelitian-penelitian yang dilakukan sebelumnya hanya menunjukkan hubungan locus of control internal dengan salah satu dimensi penyesuaian diri di perguruan tinggi seperti penyesuaian akademik atau penyesuaian sosial saja. Di sisi lain, tuntutan yang terjadi di perguruan tinggi tidak hanya berasal dari dimensi akademik maupun sosial saja, melainkan meliputi dimensi personal-emosianal dan komitmen terhadap institusi perkuliahan seperti teori yang dikemukakan oleh Baker dan Syrik (1986).

Mahasiswa tahun pertama dikatakan berhasil melakukan penyesuaian diri di perguruan tinggi apabila telah memenuhi keempat dimensi tersebut dan tidak dapat dipisahkan satu sama lain. Akan tetapi, pengukuran penyesuaian diri di perguruan tinggi secara menyeluruh meliputi keempat dimensi tersebut belum pernah dilakukan sebelumnya. Berdasarkan pemaparan tersebut, penelitian ini bermaksud untuk menguji hubungan antara locus of control internal dan penyesuaian diri di perguruan tinggi pada mahasiswa tahun pertama secara lebih komprehensif dengan menggunakan pengukuran yang meliputi keempat dimensi penyesuaian diri dari Baker dan Syrik (1986).

Dari permasalahan di atas dapat dirumuskan masalah sebagai berikut: "Apakah terdapat hubungan locus of control dan dukungan sosial dengan collage adjusment terhadap Mahasiswa Fakultas Kedokteran Universitas Malahayati tahun 2019?"

\section{METODE PENELITIAN}

Jenis penelitian yang digunakan adalah penelitian analitik observasional dengan pendekatan cross sectional yang bertujuan untuk mengetahui hubungan antara Locus of Controldan dukungan social dengan college adjustment. Tempat penelitian dilakukan di lingkungan kampus Universitas Malahayati. Penelitian dilaksanakan pada bulan Oktober - Selesai. Batasan atau kriteria yang menjadi populasi dalam penelitian ini adalah seluruh Mahasiswa Fakultas Kedokteran Universitas Malahayati tahun 2019. Sampel yang diambil dari penelitian ini adalah sebagian dari mahasiswa angkatan 2019 Fakultas Kedokteran Universitas malahayati. Cara pengambilan sampel melalui teknik Simple random sampling Pada penelitian ini yang menjadi variabel dependen nya adalah College Adjustment. Variabel independennya adalah Locus of Control, dukungan sosial. Alat ukur yang digunakan pada 
penelitian ini adalah kuesioner Locus of Control, dukungan sosialdan college adjustment. Analisis data bivariat di gunakan dalam penelitian ini adalah dengan uji Korelasi dengan bantuan program SPSS.

\section{HASIL PENELITIAN PEMBAHASAN}

DAN

Hasil penelitian diperoleh dari penyebaran kuesioner yang dilaksanakan pada bulan OktoberNovember 2020, pengambilan data selama 1 minggu. Jumlah sampel sebanyak 107 responden, yang merupakan mahasiswa Fakultas Kedokteran Universitas Malahayati angkatan 2019. Hasil pengumpulan dan pengolahan data serta analisis data responden adalah sebagai berikut:

\section{Karakteristik Responden \\ Tabel 1. Distribusi Frekuensi berdasarkan Jenis Kelamin dan Usia}

\begin{tabular}{lcc}
\hline $\begin{array}{c}\text { Jenis } \\
\text { Kelamin }\end{array}$ & $\begin{array}{c}\text { Jumla } \\
\mathrm{h}\end{array}$ & $\begin{array}{c}\text { Persentas } \\
\mathbf{e}\end{array}$ \\
\hline Laki-laki & 45 & 42.1 \\
Perempua & 62 & 57.9 \\
$\mathrm{n}$ & & \\
\hline \multicolumn{1}{c}{ Umur } & & \\
\hline 18 Tahun & 15 & 14.0 \\
19 Tahun & 61 & 57.0 \\
20 Tahun & 22 & 20.6 \\
21 Tahun & 3 & 2.8 \\
22 Tahun & 4 & 3.7 \\
23 Tahun & 2 & 1.9 \\
\hline Jumlah & $\mathbf{1 0 7}$ & $\mathbf{1 0 0 , 0}$ \\
\hline
\end{tabular}

Berdasarkan Tabel 4.1 diketahui bahwa sebagian besar responden berjenis kelamin perempuan yaitu sebanyak 62 responden $(57,9 \%)$, berusia 19 tahun yaitu sebanyak 61 responden $(57,0 \%)$.
Analisis Univariat

Tabel 2. Distribusi Frekuensi berdasarkan locus of control, Dukungan Sosial dan Collage Adjusment

\begin{tabular}{lcc}
\hline $\begin{array}{c}\text { Locus of } \\
\text { control }\end{array}$ & Jumlah & Persentase \\
\hline Eksternal & 17 & 15.9 \\
Internal & 90 & 84.1 \\
\hline $\begin{array}{l}\text { Dukungan } \\
\quad \text { Sosial }\end{array}$ & & \\
\hline $\begin{array}{l}\text { Mendukung } \\
\text { Tidak }\end{array}$ & 55 & 51.4 \\
mendukung & 52 & 48.6 \\
\hline \multicolumn{1}{c}{ Collage } & & \\
Adjusment & & \\
\hline $\begin{array}{l}\text { Tinggi } \\
\text { Rendah }\end{array}$ & 59 & 56.1 \\
\hline Jumlah & 48 & 44.9 \\
\hline
\end{tabular}

Berdasarkan gambar 2. diketahui bahwa sebagian besar responden memiliki locus of control internal yaitu sebanyak 90 responden $(84,1 \%)$, dengan dukungan sosial mendukung yaitu sebanyak 55 responden $(51,4 \%)$, dengan Collage Adjusment tinggi yaitu sebanyak 59 responden $(56,1 \%)$.

Analisis Bivariat

Tabel 3. Hubungan Locus of Control dengan College Adjustment

\begin{tabular}{|c|c|}
\hline \multicolumn{2}{|c|}{ College Adjustment } \\
\hline Locus of Control & $\begin{array}{l}p=0,000 \\
r=0,637 \\
n=107\end{array}$ \\
\hline
\end{tabular}

Berdasarkan hasil analisis dari table 3. di atas terlihat angka pearson correlation sebesar 0,637 dan diperoleh $p$-value $=0,000$ yang berarti $p<0,05$. Hal ini menunjukan Ho1 ditolak dan Ha1 diterima, maka dapat disimpulkan bahwa terdapat hubungan yang signifikan antara Locus of Control dengan college 
adjustment pada mahasiswa Fakultas Kedokteran Universitas Malahayati angkatan 2019 yaitu sebesar 0,637 dan masuk kedalam derajat hubungan yang memiliki keterkaitan tinggi dengan arah positif, artinya semakin tinggi Locus of Control responden semakin tinggi pula college adjustment responden tersebut.

Tabel 4. Hubungan Dukungan Sosial dengan College Adjustment

\begin{tabular}{cc}
\hline \multicolumn{2}{c}{ College Adjustment } \\
\hline Dukungan Sosial & $\mathrm{p}=0,000$ \\
& $\mathrm{r}=0,434$ \\
$\mathrm{n}$ & $=107$
\end{tabular}

Berdasarkan hasil analisis dari table 4. di atas terlihat angka pearson correlation sebesar 0,434 dan diperoleh $\mathrm{p}$-value $=0.000$ yang berarti $\mathrm{p}<0,05$. Hal ini menunjukan $\mathrm{Ho} 2$ ditolak dan Ha2 diterima, maka dapat disimpulkan bahwa terdapat hubungan yang signifikan antara dukungan sosialdengan college adjustment pada mahasiswa Fakultas Kedokteran Universitas Malahayati angkatan 2019 yaitu sebesar 0,434 dan masuk kedalam derajat hubungan yang memiliki keterkaitan sedang dengan arah positif, artinya semakin tinggi dukungan sosialresponden semakin tinggi pula college adjustment responden tersebut.

\section{Pembahasan}

1) Hubungan Locus Of Control Dengan Collage Adjusment

Berdasarkan hasil penelitian didapatkan dari analisa pearson correlation sebesar 0,637 dan diperoleh $\mathrm{p}$-value $=0,000$ yang berarti $p<0,05$. Yang berarti bahwa terdapat hubungan yang signifikan antara Locus of Control dengan college adjustment pada mahasiswa Fakultas Kedokteran Universitas Malahayati angkatan 2019.

Hal ini sesuai dengan teori Phares (1976) dimana mahasiswa tahun pertama memiliki locus of control maka mereka akan berusaha semaksimal mungkin untuk mengontrol perilakunya dan menyesuaikan diri dalam menghadapi perubahan dan tantangan di perguruan tinggi. Locus of control akan mendorong individu untuk berusaha mengontrol dan mengendalikan lingkungan sekitarnya karena mereka meyakini kemampuan yang dimilikinya, sehingga mereka akan cenderung mengandalkan diri mereka sendiri daripada bergantung pada orang lain. Hal ini juga digambarkan oleh Sarafino (2011) sebagai karakteristik individu dengan locus of control yang mempunyai keyakinan bahwa peristiwa dalam hidupnya terjadi sebagai hasil dari kontrol yang dilakukannya, sehingga mereka cenderung mengarahkan dirinya agar memperoleh suatu hasil yang ingin dicapainya.

Hal ini juga sejalan dengan penelitian yang dilakukan oleh Pratiwi (2017), didapatkan hasil analisa menunjukkan bahwa locus of control memberikan sumbangan sebesar $27,9 \%$ terhadap penyesuaian diri di perguruan tinggi.

Dalam kehidupan perkuliahan, mahasiswa tahun pertama yang menghadapi perubahan dan tantangan baru di perguruan tinggi dengan karakteristik ini akan menyadari bahwa untuk menghadapi tuntutan di perguruan tinggi maka dirinya perlu melakukan suatu 
usaha agar mendapat konsekuensi sesuai harapannya. Dengan adanya kesadaran tersebut, mahasiswa tahun pertama akan memiliki motivasi untuk menyesuaikan dirinya secara akademik maupun sosial dan mengaplikasikan motivasi tersebut ke dalam bentuk tindakan nyata. Ketika seorang mahasiswa tahun pertama memiliki karakter ini maka dirinya akan mampu mengatasi perubahan lingkungan dalam konteks penyesuaian sosial dan mampu mengatasi tekanan atau stress secara adaptif dalam penyesuaian personalemosionalnya di perguruan tinggi.

\section{2) Hubungan Dukungan Sosial} Dengan Collage Adjusment

Dari analisa hubungan Dukungan Sosial dengan college adjustment dengan menggunakan uji korelasi pearson diperoleh hasil terdapat hubungan yang bermakna dengan menunjukan pola positif, artinya semakin tinggi Dukungan Sosial responden maka semakin tinggi pula college adjustment responden tersebut. Hubungan antara Dukungan Sosial dengan college adjustment didapatkan sedang dengan pearson correlation sebesar 0,434 . Hasil statistik menunjukan $\mathrm{p}$-value $=0,000$ yang berarti terdapat hubungan yang bermakna antara Dukungan Sosialdengan college adjustment pada mahasiswa Fakultas Kedokteran Universitas Malahayati angkatan 2019. Hal ini sesuai dengan teori Sarafino (2011) bahwa diterimanya dukungan sosial dari berbagai pihak, maka proses penyesuaian diri di lingkungan kampus dapat lebih mudah dijalani.
Hal ini sesuai dengan penelitian Novalia (2004) yang menyebutkan bahwa salah satu faktor yang berperan dalam proses penyesuaian diri di lingkungan kampus pada mahasiswa Fakultas Psikologi Unpad adalah faktor eksternal berupa teman yangdapat memberikan dukungan sosial bagi mahasiswa. Kehadiran teman dapat menjadi sumber dukungan sosial terutama ketika mahasiswa ingin berbagi pengalaman atau kejadian yang dialaminya. Splichal (2009) juga mengungkapkan bahwa mahasiswa yang kesulitan dalam menyesuaikan diri dengan lingkungan kampus seringkali menyatakan bahwa mereka mengharapkan adanya seseorang yang membantu, mengarahkan atau memberikan dukungan emosional supaya mereka dapat menyesuaikan diri dengan baik. Artinya, kemampuan penyesuaian diri mahasiswa Fakultas Psikologi Unpad kemungkinan dipengaruhi oleh adanya dukungan sosial dari lingkungan sekitar mahasiswa.

Begitu pula pada mahasiswa baru angkatat 2019 di Fakultas Kedokteran Malahayati, dimana individu yang mendapatkan dukungan sosial percaya bahwa mereka dicintai, dihargai, serta dianggap sebagai bagian dari jaringan sosial, seperti keluarga dan organisasi kemasyarakatan. Jika dikaitkan dengan penyesuaian diri pada mahasiswa di lingkungan kampus, maka mahasiswa yang mendapatkan dukungan sosial pada saat awal memasuki perguruan tinggi percaya bahwa mereka dicintai, dihargai, serta dianggap sebagai bagian dari kampus. Dukungan sosial yang diterima oleh mahasiswa dapat berasal dari 
berbagai pihak, seperti orangtua, fakultas, senior, dan teman sebaya.

\section{KESIMPULAN}

1. Sebagian besar responden yang memiliki locus of control sedang yaitu sebanyak 90 responden $(84,1 \%)$.

2. Sebagian besar responden dengan dukungan sosial mendukung yaitu sebanyak 55 responden $(51,4 \%)$.

3. Sebagian besar responden dengan Collage Adjusment tinggi yaitu sebanyak 56 responden $(52,3 \%)$.

4. Ada hubungan antara Locus of Control Dengan Collage Adjusment Terhadap Mahasiswa Fakultas Kedokteran Universitas Malahayati tahun 2019.

5. Ada hubungan antara Dukungan Sosial Dengan Collage Adjusment Terhadap Mahasiswa Fakultas Kedokteran Universitas Malahayati tahun 2019.

\section{SARAN}

\section{Bagi Masyarakat}

Peneliti berharap orangtua menyadari bahwa dukungan yang diberikan bagi anaknya sangatlah berarti di masa awal perkuliahan walaupun orangtua dan anak berada berjauhan. Meningkatkan dukungan dalam aspek Social Integration yaitu mempunyai kesempatan untuk berbagi minat dan kesenangan dan melakukan aktifitas yang sama terutama saat anak kembali kerumah diwaktu libur dan mempertahankan aspek Reliable aliance yang diberikan. Dukungan tersebut dapat membantu anaknya untuk menghadapi lingkungan yang baru. Selain itu, dukungan yang diberikan oleh orangtua dapat meningkatkan kesehatan fisik dan psikologis pada diri anak, serta mendorong anak meraih pencapaian terbaiknya di jenjang perkuliahan. Dukungan tidak selalu harus bersifat materi. Dukungan dapat juga ditunjukkan dalam bentuk perhatian, menjalin komunikasi, membantu mencarikan solusi apabila anak menghadapi kesulitan, dan berbagai bentuk dukungan lainnya.

2. Bagi Institusi

Penyesuaian diri yang baik yang dimiliki mahasiswa tahun pertama pada suatu perguruan tinggi menunjukkan bahwa perguruan tinggi telah cukup mampu membangun lingkungan yang mendukung penyesuaian diri mahasiswanya. Oleh karena itu, perguruan tinggi perlu mempertahankan kegiatankegiatan yang memfasilitasi penyesuaian diri mahasiswa seperti kegiatan inisiasi dan metode pembelajaran yang sesuai dengan kebutuhan mahasiswa.

3. Bagi Peneliti Selanjutnya

Diharapkan peneliti tidak membatasi kriteria subjek penelitian supaya lebih banyak data tambahan yang didapatkan dari subjek penelitian. Selain itu, subjek penelitian dapat lebih bervariasi dengan melibatkan mahasiswa darilebih banyak fakultas atau lebih banyak universitas agar data yang didapatkan lebih dapat digeneralisasikan dan bermanfaat bagi banyak pihak.

\section{DAFTAR PUSTAKA}

Abdullah, Elias, Jegak. (2009). Relationship Between Coping And University Adjustment And Academic Achievment Among First Year Undergraduates In A Malaysian Public University. 
International Journal of Art and Science, 2(11), 379-392.

Abe, J., Talbot, D., \& Geelhoed, R. (1998). Effects of a Peer Program on International Student Adjustment. Journal of College Student Development, Vol, 39 (6).

Al-Khatib, Awamleh, dan Samiwi. (2012). Student's Adjustment To Collage Life At Albalqa Applied University. American International Journal of Contemporary Research Vol. 2 No. 11, 7-17.

Ali dan Asrori. (2005). Psikologi Remaja: Perkembangan Peserta Didik. Jakarta: Bumi Aksara.

Arkoff. (2013). Adjustment And Mental Health. New York: McGraw-Hill.

Baker, R., McNeil, O.V., \& Siryk, B. (1985). Expectation and reality in freshman adjustment to college. Journal of Counseling Psychology, Vol. 32 (1).

Baker, R., \& Siryk, B. (1984). Measuring Adjustment to College. Journal of Counseling Psychology, Vol. 31 (2).

Baker, R., \& Siryk, B. (1989). Student Adaptation to College Questionnaire (SACQ). LoS Angeles: Western Psychological Services.

Boeree. (2008). Personality Theories: Melacak Kepribadian Anda Bersama Psikologis Dunia.Yogyakarta: Prismashopie.

Brownell. (2002). Childhood Peer Relationship: Social Acceptance, Friendship, And Peer Networks. Journal of School Psychology, 41, 235284.

Brier dan Paul. (2011). Skill in Solution Focused Brief Counseling And
Psychotherapy. Sage Publication: London.

Brissette, I., Scheier, M.F., Carver., C.S. (2002). The Role of Optimism in Social Network Development, Coping, and Psychological Adjustment During a Life Transition. Journal of Personality and Social Psychology. Vol. 82, No.1.

Budiyanto. (2015). Hubungan Antara Dukungan sosial Dengan Penyesuaian Diri Di Lingkungan Kampus Pada Mahasiswa Psikologi Universitas Padjajaran. Bandung: Fakultas Psikologi UNPAD.

Cohen. (2003). Stress, Social Support And The Buffering Hypothesis. Psychological Bulletin, 98, 310-357.

Crandal, Katkovsky, dan Crandal. (2005). Children's Beliefs InTheir Own Control of Reinforcements In Intellectual-Academic Achievment Situations. Child Development, 91-109.

Crede, M., \& Niehorster, S. (2012). Adjustment to College as Measured by the Student Adaptation to College Questionnaire: A Quantitative Review of its Structure and Relationships with Correlates and Consequences. Albany, New York: State University of New York.

Crider. (2003). Psychology. Scott, Foresman \& Company.

Cutrona E.C. (2016). Social Support in Couples. New Delhi: SAGE Publications,. Inc.

Estiane, U. (2015). Pengaruh Dukungan Sosial Sahabat terhadap Penyesuaian Sosial Mahasiswa Baru di Lingkungan Perguruan Tinggi. Jurnal Psikologi Klinis dan Kesehatan 
Mental Vol. 4 No. 1. Universitas Airlangga Surabaya.

Gerdes dan Mallinckrodt. (2004).

Emotional, Social, And Academic Adjustment of Collage Students: A Longitudinal Study of Retention. Journal of Counseling and Development: JCD, 72(3), 281.

Gray. (2013). Research On Retention And Arttrition. Does Money Matter: Millenium Research Series, No 6. Montreal: The Canada Millenium Scholarship Foundation.

Gutama, P.S. (2004). Hubungan antara Locus of Control Eksternal dengan Kecemasan terhadap Kegagalan pada Mahasiswa Tahun Pertama. Yogyakarta: Fakultas Psikologi Universitas Islam Indonesia.

Julia dan Veni. (2012). Hubungan Antara Kecerdasan Spiritual Dan Kematangan Emosi Dengan Penyesuaian Diri Pada Remaja. Jurnal Psikologi, Vol.2 (2), 131-145.

Lapsley, Rice, dan Fitz Gerald. (2010). Adolescent Attachment, Identity, And AdjustmentTo Collage: Implication For The Continuity of Adaptation Hypothesis. Journal of Counseling \& Development, 2(2), 121-133.

Hurlock. (2010). Psikologi Perkembangan, Suatu Pendekatan Sepanjang Rentang Kehidupan. Jakarta: Airlangga.

Kreitner dan Kinicki. (2001). Perilaku Organisasi Diterjemahkan Oleh Erly Suandy. Jakarta: Salemba Empat.

Martin, Swartz, dan Carver. (2014). The Effect Of Freshman Orientation And Locus of Control On Adjustment To
Collage: A Follow Up Study. Social Behavior and Personality: An International Journal, 22(2), 201-208.

Meliza, D. (2012). Hubungan antara Psychological Well-Being dan College Adjustment pada Mahasiswa Tahun Pertama Universitas Indonesia. Jakarta: Universitas Indonesia.

Monks. (2012). Psikologi Perkembangan. Yogyakarta: Unieversitas Gajah Mada.

Morgans, K. A. (2012). The Social and Academic Adjustments of Students to College Life. Naational Undergraduate Research Clearinghouse, 5. Diakses pada Januari 2016, tersedia online: http://www.webclearinghous e.net/volume/.

Notoadmodjo. (2015). Metodologi Penelitian Kesehatan. Jakarta: Rineka Cipta.

Nurdin. (2009). Pengaruh Kecerdasan Emosional Terhadap Penyesuaian Sosial Siswa Di Sekolah. Jurnal Administrasi Pendidikan, Vol IX, No.1, April 22009.

Phares. (1976). Locus of Control In Personality. New Jarsey: General Learning Press.

Pratiwi. (2017). Hubungan Antara Locus Of Control Internal Dan Penyesuaian Diri Di Perguruan Tinggi Pada Mahasiswa Tahun Pertama. Yogyakarta: Fakultas Psikologi.

Rotter. (2006). Generalized Expectancies For Internal Versus Exterbal Control of Reonforcement.

Phsychological Monograph: General and Applied, 80(1), 1.

Rosiana, D. (2006). Penyusunan Modul Pelatihan Penyesuaian Diri Akademis Bagi Mahasiswa Tingkat Pertama Fakultas Psikologi Unisba. Jakarta: 
Fakultas Psikologi Universitas Indonesia.

Salam. (2014). Cara Belajar Yang Sukses Di Perguruan Tinggi. Jakarta: PT Rineka Cipta.

Sarafino dan Smith. (2008). Health Psychology Biopsychosicial Interaction. United States of America: John Wiley \& Sons, Inc.

Sarason, B.R., Pierce, G.R., Sarason, I.G. (1990). Social Support an Interactional View. New York: John Willey.

Sarason, B.R. Et al. (1987). Interrelations of Social Support Measures : Theoritical and Practical Implications. Journal of Personality and Social Psychology. 52.

Sarason, I.G. et al. (2010). Assessing Social Support: The Social Support Questionnaire. Journal of Personality and Social Psychology. Vol 44 No. 1.

Schneiders, A.A. (2014). Personal Adjustment and Mental Health. New York: Holt, Rinehart and Winston.

Sharma. (2012). Adjustment and Emotional Maturity Among First Year Collage Students. Pakistan Journal of Social and Clinical Psychology, 10(2), 3237.

Sujana. (2014). Pengetahuan Dasar Bagi Mahasiswa Baru Memasuki Perguruan Tinggi. Surabaya: UPT-MKU Universitas Airlangga.

Syah. (2014). Psikologi Belajar. Ed Rev-12. Jakarta: PT Raja Grafindo Persada.

Thoits. (2015). Stress, Coping And Social Support Proccesses. Journal of Health and Social Behavior, 36 (Suppl.1), 53-79.

Tinto. (2013). Leaving Collage: Rethinking The Causes And Cures of Students Attrition.
Second Edition. Chicago: University of Chicago Press.

Tokuno. (2016). The Early Adult Transition And Friendship: Mechanism of Support. Adolescene, 21, 293-606.

White dan Watt. (2014). The Abnormal Psychology. New York: John Wiley and Sons, Inc.

Zimet, Dahlem, dan Karley. (2008). The Multidimensial Scale of Percieved Social Support. Journal of Personality Assesment, 52, (1), 31-40 